\title{
Role of admission cardiotocography and amniotic fluid index on perinatal outcome in low risk pregnancy at term
}

\author{
Mansi Patnaik, Tejaswini M.*, Sudhanshu Kumar Rath, Shaik Afrah Naaz
}

Department of Obstetrics and Gynecology, KIMS, Bhubaneswar, Odisha, India

Received: 07 February 2021

Accepted: 09 March 2021

\section{*Correspondence:}

Dr. Tejaswini M.,

E-mail: mtejaswini81@gmail.com

Copyright: (C) the author(s), publisher and licensee Medip Academy. This is an open-access article distributed under the terms of the Creative Commons Attribution Non-Commercial License, which permits unrestricted non-commercial use, distribution, and reproduction in any medium, provided the original work is properly cited.

\begin{abstract}
Background: Fetal surveillance even in normal or low risk pregnancy is essential to ensure safe parturition with minimum intervention. Cardiotocography (CTG) and clinical estimation of amniotic fluid volume (AFV) measured as amniotic fluid index (AFI) are two tests that are easily available in the labor room and can be used to identify fetal well-being. Our study aimed to evaluate role of admission cardiotocography (CTG) and amniotic fluid index (AFI) on perinatal outcome in low risk pregnancy at term.

Methods: The study was conducted as a prospective observational study. All low risk pregnant women at term admitted to the labor ward in early or established labour between September 2018 and August 2020 were included in the study. They underwent admission CTG and AFI assessment using ultrasonography. All parameters including CTG changes, mode of delivery, AFI, presence of meconium, APGAR score at 1 and 5 mins, need for admission in neonatal ICU and perinatal mortality were recorded. Quantitative data was compared using chi square test.

Results: A total of 180 patients were included in the study. Majority of the women belonged to the age group of 3035 years. Abnormal CTG showing fetal distress was seen in $105(58.33 \%)$ cases. Non-reactive CTG was significantly associated with meconium stained liqour, requirement for LSCS, still birth, fetal distress, APGAR $<7$ at 1 and $5 \mathrm{~min}$ and NICU admission $(\mathrm{p}<0.001)$. The association of low AFI with non-reactive CTG had statistically significant impact on perinatal outcomes like low birth weight, requirement for LSCS, fetal distress, APGAR $<7$ at 1 and 5 mins and NICU admissions.

Conclusions: Admission CTG is a simple non-invasive test that can serve as a screening tool in low risk obstetric population to detect fetal distress already present or likely to develop and prevent unnecessary delay in intervention. Thus, it may help in preventing fetal morbidity and mortality.
\end{abstract}

Keywords: Amniotic fluid, Cardiotocography, Fetal distress, Meconium

\section{INTRODUCTION}

Normal or low-risk pregnancy constitutes majority of pregnant population. Foetal surveillance during labour is necessary to ensure safe passage of the foetus from an intrauterine to an extra uterine environment with minimum intervention. A number of technical breakthroughs occurred in the $20^{\text {th }}$ century that led to development of admission Cardio-tocography (CTG) in the 1960 's to monitor fetal heart rate and uterine contractions. $^{1}$ Clinical estimation of amniotic fluid volume (AFV) measured as Amniotic fluid index (AFI) is another important part of fetal assessment as variation in its amount has been related to the outcome of pregnancy. Both the above methods are routinely used in clinical practice to identify fetal well-being as they are quick and easily accessible in the labor room.

Admission Cardiotocography (CTG) is a screening test that involves electronic recording of fetal heart rate 
(FHR) and uterine activity for approximately 20 minutes. $^{2}$ The CTG can be reactive or nonreactive. If it is non-reactive test will be repeated after 1 hour and decision will be taken according to repeat CTG traces. ${ }^{3}$ If the test is reactive then labor will be allowed to progress in usual manner. Although intermittent auscultations can measure the baseline fetal heart rate (FHR), other features such as baseline variability, accerlations and decelerations in response to the uterine contraction remains unappreciated by simple auscultation. ${ }^{4}$ Ingemarsson et al. described CTG as an alternative method of monitoring FHR during labour to pick the women apparently at risk where the fetus was compromised on admission or were likely to be compromised in labour. ${ }^{5}$

Amniotic fluid index (AFI) quantification is an important component of the biophysical profile in ultrasound evaluation of fetal well-being, especially in the third trimester. ${ }^{6}$ Amount of the amniotic fluid volume has been linked to fetal compromise with perinatal morbidity approaching more than $50 \%$ in polyhydramnios and almost $80 \%$ in severe oligohydramnios. ${ }^{7}$ Estimation of amniotic fluid is usually done using the four quadrant technique as described by Phelan et al. ${ }^{8}$ Aims and objectives of the study were to evaluate role of admission cardiotocography (CTG) and Amniotic fluid index (AFI) on perinatal outcome in low risk pregnancy at term and to determine if abnormal CTG and AFI are associated with increase in obstetrical interventions.

\section{METHODS}

The study was conducted as a prospective observational study. All low risk pregnant women at term, booked or unbooked, admitted to the labor ward in early or established labour between September 2018 and August 2020 were included in the study. The study was conducted at the Department of Obstetrics and Gynacology, Kalinga Institute of Medical Sciences, Bhubaneswar.

\section{Inclusion criteria}

All term patients (37 weeks - 40 weeks), singleton pregnancy, non-anomalous baby, intact membranes, primigravida and multigravida were included in the study.

\section{Exclusion criteria}

Recurrent missed abortions, previous caesarean section, maternal medical disorders, previous bad obstetric history, multiple pregnancies, maternal age (above 40 years and or below 19 years) were excluded from the study.

All patients satisfying the inclusion criteria were included in the study after obtaining an informed consent. The detailed history and clinical examination was performed for all these patients. They underwent admission CTG and AFI assessment using ultrasonography. Parameters studied included CTG changes (According to NICE criteria for CTG interpretation). ${ }^{9}$ Mode of delivery (normal vaginal delivery, caesarean section, instrumental delivery), AFI, Presence of meconium, APGAR score at 5 minutes, need for admission in neonatal unit, perinatal mortality.

\section{Statistical analysis}

All characteristics were summarized descriptively. For categorical data, the number and percentage were used in the data summaries and diagrammatic presentation. Quantitative data was compared using Chi square test. $\mathrm{p}<0.05$ was considered significant. Data analysis was done using STATA software version 15.1

\section{RESULTS}

Table 1: The various variables studied.

\begin{tabular}{|c|c|c|}
\hline Variables & Frequency & $\%$ \\
\hline \multicolumn{3}{|l|}{ Parity } \\
\hline Multi & 56 & 31.11 \\
\hline Primi & 124 & 68.89 \\
\hline \multicolumn{3}{|l|}{ AFI } \\
\hline $\mathrm{AFI}>5$ & 100 & 55.56 \\
\hline $\mathrm{AFI}<5$ & 80 & 44.44 \\
\hline \multicolumn{3}{|l|}{ CTG } \\
\hline Reactive & 105 & 58.33 \\
\hline Non reactive & 75 & 41.67 \\
\hline \multicolumn{3}{|l|}{ Liqour } \\
\hline Meconium stained & 110 & 61.11 \\
\hline Non meconium stained & 70 & 38.89 \\
\hline \multicolumn{3}{|l|}{ Low Birth Weight } \\
\hline Absent & 167 & 92.78 \\
\hline Present & 13 & 7.22 \\
\hline \multicolumn{3}{|l|}{ Mode of delivery } \\
\hline VD & 83 & 46.11 \\
\hline LSCS & 97 & 53.89 \\
\hline \multicolumn{3}{|l|}{ Perinatal mortality } \\
\hline Absent & 176 & 97.78 \\
\hline Present & 4 & 2.22 \\
\hline \multicolumn{3}{|l|}{ Fetal distress } \\
\hline Absent & 75 & 41.67 \\
\hline Present & 105 & 58.33 \\
\hline \multicolumn{3}{|l|}{$\mathrm{APGAR}<7$ at $1 \mathrm{~min}$} \\
\hline Absent & 73 & 40.08 \\
\hline Present & 106 & 59.22 \\
\hline \multicolumn{3}{|l|}{ APGAR $<7$ at $5 \mathrm{~min}$} \\
\hline Absent & 94 & 52.51 \\
\hline Present & 85 & 47.49 \\
\hline \multicolumn{3}{|l|}{ NICU admission } \\
\hline Not required & 94 & 50.28 \\
\hline Required & 85 & 49.49 \\
\hline
\end{tabular}


Table 2: Correlation of AFI with respect to age, gestational age and birth weight.

\begin{tabular}{|llll|}
\hline Variables & $\begin{array}{l}\text { AFI }>5 \\
(\mathbf{M} \pm \mathbf{S D})\end{array}$ & $\begin{array}{l}\mathbf{A F I}<5 \\
(\mathbf{M} \pm \mathbf{S D})\end{array}$ & $\begin{array}{l}\mathbf{P} \\
\text { value }\end{array}$ \\
\hline Age & $29.17 \pm 2.91$ & $28.9 \pm 2.5$ & 0.5138 \\
\hline $\begin{array}{l}\text { Gestational } \\
\text { age }\end{array}$ & $38.55 \pm 1.0766$ & $38.65 \pm 1.0445$ & 0.531 \\
\hline $\begin{array}{l}\text { Birth } \\
\text { weight }\end{array}$ & $2.785 \pm 0.305$ & $2.605 \pm 0.505$ & 0.0036 \\
\hline *p<0.05 is significant & & \\
\hline
\end{tabular}

The mean of the study group was $29.05 \pm 2.7$ years with majority of the women belonging to the age group of 30-35 years. Majority of the patients were primigravida (124 (68.89\%)). CTG was reactive in $58.33 \%$ cases. AFI of $\leq 5 \mathrm{~cm}$ was detected in $44.4 \%$ cases. Meconium stained liqour was seen in 110 $(61.11 \%)$ cases. Birth weight was found to be below normal in $13(7.22 \%)$ cases.

Abnormal CTG showing fetal distress was seen in 105 $(58.33 \%)$ cases. APGAR score of less than 7 at 1 min was seen in $107(59.22 \%)$ cases and at $5 \mathrm{~min}$ in $85(47.49 \%)$ newborns. $89(49.72 \%)$ required admission to NICU. Still birth was recorded in 4 cases $(2.22 \%)$ (Table 1$)$. Correlation between low birth weight, AFI $<5 \mathrm{~cm}$ and non-reactive CTG was found to be statistically significant $(\mathrm{p}<0.001)$ (Table 2, 3, 4). Low AFI was associated more with low birth weight and requirement for LSCS and this association was also found to be statistically significant $(\mathrm{p}<0.001)($ Table 5).
Table 3: Correlation of AFI and CTG with respect to age, gestational age and birth weight.

\begin{tabular}{|llll|}
\hline & $\begin{array}{l}\text { Outcomes } \\
\text { with respect } \\
\text { to AFI>5 and } \\
\text { reassuring } \\
\text { CTG } \\
\text { (mean } \pm \text { SD) }\end{array}$ & $\begin{array}{l}\text { Outcomes } \\
\text { with respect } \\
\text { to AFI<5 } \\
\text { and non- } \\
\text { reassuring } \\
\text { CTG } \\
\text { (mean } \pm \text { SD) }\end{array}$ & $\begin{array}{l}\text { P value } \\
\text { Age }\end{array}$ \\
\hline $\begin{array}{l}\text { Gestational } \\
\text { age }\end{array}$ & $38.5 \pm 1.06$ & $38.82 \pm 1.028$ & 0.162 \\
\hline $\begin{array}{l}\text { Birth } \\
\text { weight }\end{array}$ & $2.76 \pm 0.34$ & $2.45 \pm 0.5$ & 0.0001 \\
\hline
\end{tabular}

$* \mathrm{p}<0.05$ is significant

Table 4: Correlation of CTG with respect to age, gestational age and birth weight.

\begin{tabular}{|llll|}
\hline & $\begin{array}{l}\text { Reactive } \\
\mathbf{M} \pm \mathrm{SD}\end{array}$ & $\begin{array}{l}\text { Non reactive } \\
\mathbf{M} \pm \mathrm{SD}\end{array}$ & $\begin{array}{l}\mathrm{P} \\
\text { value }\end{array}$ \\
\hline Age & $29.057 \pm 2.87$ & $29.04 \pm 2.58$ & 0.967 \\
\hline $\begin{array}{l}\text { Gestational } \\
\text { age }\end{array}$ & $38.533 \pm 1.038$ & $38.68 \pm 1.092$ & 0.361 \\
\hline $\begin{array}{l}\text { Birth } \\
\text { weight }\end{array}$ & $2.8 \pm 0.341$ & $2.57 \pm 0.47$ & 0.0002 \\
\hline
\end{tabular}

$* \mathrm{p}<0.05$ is significant.

Table 5: Correlation of perinatal outcomes with respect to AFI.

\begin{tabular}{|llll|}
\hline Meconium stained & AFI >5 & AFI <5 & P value \\
\hline Low birth weight & $37(52.86 \%)$ & $33(47.14 \%)$ & 0.561 \\
\hline LSCS & $1(7.69 \%)$ & $12(92.31 \%)$ & 0.001 \\
\hline Still birth & $44(45.36 \%)$ & $53(54.64 \%)$ & 0.003 \\
\hline Fetal distress & $1(25 \%)$ & $3(75 \%)$ & 0.042 \\
\hline APGAR<7 at 1 min & $49(46.67 \%)$ & $56(53.33 \%)$ & 0.047 \\
\hline APGAR<7 at 5 min & $47(44.34 \%)$ & $59(55.66 \%)$ & 0.940 \\
\hline NICU admission & $42(49.41 \%)$ & $43(50.59 \%)$ & 0.176 \\
\hline
\end{tabular}

$* \mathrm{p}<0.05$ is significant

Table 6: Correlation of perinatal outcomes with respect to CTG.

\begin{tabular}{|llll|}
\hline Meconium stained & CTG (reactive) & CTG (Non -reactive) & P value \\
\hline Low birth weight & $28(40 \%)$ & $42(60 \%)$ & 0.001 \\
\hline Mode of delivery $(\mathbf{C S})$ & $4(30.77 \%)$ & $9(69.23 \%)$ & 0.036 \\
\hline Perinatal mortality & $32(32.99 \%)$ & $65(67.01 \%)$ & 0.001 \\
\hline Fetal Distress & $41(39.05 \%)$ & $3(75 \%)$ & 0.171 \\
\hline Apgar $<$ 7 at 1mins & $39(36.79 \%)$ & $64(60.95 \%)$ & 0.001 \\
\hline Apgar $<$ 7 at 5 mins & $26(30.59 \%)$ & $67(63.21 \%)$ & 0.001 \\
\hline NICU admission & $31(34.83 \%)$ & $59(69.41 \%)$ & 0.001 \\
\hline
\end{tabular}

$* \mathrm{p}<0.05$ is significant

Non-reactive CTG was significantly associated with meconium stained liqour, LSCS, still birth, fetal distress,
APGAR $<7$ at 1 and $5 \mathrm{~min}$ and NICU admission $(\mathrm{p}<0.001)$ (Table 6). 
Table 7: Correlation of perinatal outcomes with respect to AFI and CTG

\begin{tabular}{|llll|}
\hline & Reactive CTG+AFI>5 & Non-Reactive CTG+AFI<5 & P value \\
\hline Meconium stained & $51(72.86 \%)$ & $19(27.14 \%)$ & 0.024 \\
\hline IUGR & $5(38.46 \%)$ & $1(61.54 \%)$ & 0.001 \\
\hline MOD of delivery & $65(67.01 \%)$ & $32(18.89 \%)$ & 0.001 \\
\hline Perinatal mortality & $3(75 \%)$ & $1(25 \%)$ & 0.75 \\
\hline Fetal Distress & $76(72.38 \%)$ & $29(27.62 \%)$ & 0.001 \\
\hline Apgar $<$ 7 at 1 mins & $76(71.70 \%)$ & $30(28.30 \%)$ & 0.001 \\
\hline Apgar<7 at 5mins & $57(67.06 \%)$ & $28(32.94 \%)$ & 0.001 \\
\hline NICU Admission & $63(70.09 \%)$ & $26(29.21 \%)$ & 0.001 \\
\hline
\end{tabular}

$* \mathrm{p}<0.05$ is significant.

The association of low AFI with non-reactive CTG has statistically significant impact on perinatal outcomes like low birth weight, requirement for LSCS, fetal distress, APGAR $<7$ at 1 and 5 mins, and NICU admissions (Table 7).

\section{DISCUSSION}

In our study, out of 180 enrolled subjects, majority belonged to age group of 30-35 years (80\%).This correlated with the study by Hafizur et al., in which $42.5 \%$ of the patients were in 25-30 years age group. ${ }^{10}$ While in the study by Kansal et al., majority of patients belonged to the age group 26-30 years age (44\%). ${ }^{11}$ $68.89 \%$ of the patients were nulliparous while $31.11 \%$ were multiparous which were comparable with the results of the study by Kumari et al; where $56 \%$ were nulliparous and $44 \%$ were multiparous. ${ }^{12}$ According to the $20 \mathrm{~min}$ admission CTG tracing done in our subjects, $58.33 \%$ had reactive CTG and $44.44 \%$ had abnormal CTG which was comparable to the study by Hafizur et al. ${ }^{11}$ These results were also comparable to the study by Xavier et al. ${ }^{13}$

Out of the 105 patients with reactive CTG, $32(32.99 \%)$ delivered vaginally, while non-reactive CTG 65 (67.01\%) were delivered by caesarean section. Thus, the incidence of vaginal deliveries was common when there was reactive CTG as compared to LSCS. On the other hand, caesarean sections were more in the non-reactive CTG group. This result was comparable to those of Hafizur et al. ${ }^{11}$ In another study by Meena et al, $92 \%$ patients with reactive CTG delivered vaginally and only $6.67 \%$ required $\mathrm{LSCS}^{14}$

Among the 180 patients, $110(61.11 \%)$ had nonmeconium stained liquor and $70(38.89 \%)$ had meconium stained liquor. Among these 70 patients, $42(60 \%)$ had non-reactive CTG and $28(40 \%)$ had reactive CTG. The APGAR score at 1 and 5 minutes of less than 7 were recorded in $67(63.21 \%)$ and $59(69.41 \%)$ newborns respectively. Among the patients with non-reactive CTG, $58(65.17 \%)$ newborns needed NICU admission. 64 $(60.95 \%)$ babies had fetal distress. The perinatal mortality was higher in patients with non-reactive CTG $(3.75 \%)$. Thus the incidence of fetal distress and poor neonatal outcome was more in the patients with nonreactive CTG in our study.

Das et al., conducted a prospective study to prove the efficacy of admission test in predicting fetal jeopardy during labour. ${ }^{15}$ They reported that incidence of fetal distress and chances of caesarean delivery were higher in the abnormal admission test group. A study done by Hafizur et al. had results similar to our study. ${ }^{11}$

Gupta et al., had reported $66.2 \%$ meconium stained liquor, $58.1 \%$ had APGAR $<7$ at $5 \mathrm{~min}$ and $75.7 \% \mathrm{NICU}$ admission in non-reassuring CTG group. ${ }^{16}$ In a prospective study by Panda et al., reassuring CTG group had $4.65 \%$ meconium stained liquor, $3.48 \%$ APGAR $<7$ at $5 \mathrm{~min}$ and $9.3 \%$ NICU admissions; non-reassuring CTG group had $85.71 \%$ meconium stained liquor, $28.57 \%$ had APGAR $<7$ at $1 \mathrm{~min}$ and $78.57 \%$ newborns needed NICU admission. ${ }^{17}$

In study of Maha et al on amniotic fluid index predictor of perinatal outcome found $27 \%$ cases of caesarean belong to $\mathrm{AFI}<5 \mathrm{~cm}$ group with meconium staining in $42 \%$ cases and 5 min APGAR of $<7$ in $16 \%$ cases with NICU admission in $16 \%$ cases. Out of these findings meconium staining in AFI $<5 \mathrm{~cm}$ group was statistically significant $(p=0.004) .{ }^{20}$ In our study $54 \%$ cases of caesarean belong to $\mathrm{AFI}<5 \mathrm{~cm}$ group with meconium staining in $47.14 \%$ and 5 min APGAR of $<7$ in $50.59 \%$ with requirement of NICU admission in $52.81 \%$ cases. In our study low birth weight was statistically significant with $\mathrm{AFI}<5 \mathrm{~cm}$ group. In another study by Bachhav et al, AFI measurement on uncomplicated pregnancy revealed $66 \%$ caesarean rate in $\mathrm{AFI}<5 \mathrm{~cm}$ group, which was similar to our study. ${ }^{2}$ In our study it was found that $\mathrm{AFI}<5$ and non-reassuring $\mathrm{CTG}$ together were significantly related to most of the perinatal outcome measures like mode of delivery, fetal distress, APGAR at 1 and 5 minutes and NICU admissions.

\section{CONCLUSION}

Pregnancy with no high risk constitutes a major part of pregnant population and it is equally important to predict adverse even in them. For predicting the perinatal outcome in low risk pregnancy, we adopted admission 
CTG with AFI by using ultrasound. In the present study, $\mathrm{AFI}<5 \mathrm{~cm}$ was associated with cesarean delivery, particularly for fetal distress and low birth weight babies. A non-reactive CTG showed a significant correlation with requirement of caeserian section and all perinatal outcomes except low birth weight and perinatal mortality.

Admission CTG is a simple non-invasive test that can serve as a screening tool in low risk obstetric population to detect fetal distress already present or likely to develop and prevent unnecessary delay in intervention. Thus, it may help in preventing fetal morbidity and mortality. As, the test has high specificity it has role in obstetric wards of non-industrialized countries with heavy workload and limited resources to help in triaging.

\section{ACKNOWLEDGEMENT}

Authors would like to thank Dr. Saswat Subhankar, Asst. Professor, Dept. of Respiratory Medicine, Kalinga Institute of Medical Sciences for his guidance in preparing this manuscript.

Funding: No funding sources

Conflict of interest: None declared

Ethical approval: The study was approved by the Institutional Ethics Committee

\section{REFERENCES}

1. Mehta M, Sau A. Fetal heart rate monitoring. In Editors Roger KF, Thomas JG, Michael PN, Lisa AM. The Obstetrician and Gynaecologist. Lippencott Williams and Wilkins; $4^{\text {th }}$ Revised Edition. 2014:75.

2. Ingemarsson I. In: Intrapartum foetal surveillance. Spencer JAD, Ward RHT, editors. London: Royal College of Obstetricians and Gynaecologists. Electronic foetal monitoring as a screening test. 1993:45-52.

3. Lekis S, Loghis C, Parayoto N. Use of antepartum and intrapartum cardiography. Clin Exp Obstet Gynaecol. 1997;24:79-81.

4. Gibb D, Arulkumaran S. Oxford: Boston: Butterworth-Heinemann. The admission test: Clinical scenarios Foetal monitoring in practice. 1997:67-72.

5. Ingemarsson I, Arulkumaran S, Ingemarsson E, Tambyraja RL, Ratnam SS. Admission test: a screening test for foetal distress in labor. Obstet Gynecol. 1986;68(6):800-6.

6. Kofinas A, Kofinas G. Differences in amniotic fluid patterns and fetal biometric parameters in third trimester pregnancies with and without diabetes. J Maternal-Fetal Neonatal Med. 2006;19(10):633-8.

7. Magann E, Sandlin A, Ounpraseuth S. Amniotic fluid and the clinical relevance of the sonographically estimated amniotic fluid. J Ultrasound Med. 2011;30(11):1573-85.

8. Phelan JP, Ahn MO, Smith CV, Rutherford SE, Anderson E. Amniotic fluid index measurements during pregnancy. J Reprod Med. 1987;32(8):601-4.

9. NICE. Inherited clinical guideline $C$. The use of electronic fetal monitoring. London: National Institute of Clinical Excellence. 2001.

10. Rahman H, Renjhen P, Dutta S, Kar S. Admission cardiotocography: its role in predicting foetal outcome in high-risk obstetric patients. Aust Med J. 2012;5(10):522-7.

11. Kansal R, Goel G, Mangala D, Garg P, Verma K, Geetika. Correlation of admission test with neonatal outcome. Peoples J Scientific Res. 2014;7(1):27-31.

12. Kumari VR, Indiramani, Chakravarthy K. A comparative study of perinatal outcome in low risk pregnancies with CTG monitoring and intermittent auscultation. J Evolution Med Dental Sci. 2015;4(105):17038-42.

13. Xavier AA, Pandey D, Dogra L, Lewis LE. Cardiotocography in a perinatal armamentarium: boon or bane? Int J Reprod Contracept Obstet Gynecol. 2015;4:2000-4.

14. Meena RB, Vyas L, Meena BS, Khandelwal A. Perinatal outcome by admission cardiotocography in low-risk obstetric population. Int J Advance Res Development. 2017; 2(3):13-8.

15. Das V, Katiyar N, Malik GK. Role of admission test J Obstet Gynecol Ind. 2001;51(1):48-50.

16. Gupta M, Nagar T, Gupta P. Role of cardiotocography to improve perinatal outcome in high risk pregnancy. Int $\mathrm{J}$ Contemporary Med Res. 2017;4(4):853-6.

17. Panda S, Das A, Nowroz HM, Singh AS. Role of admission tests in predicting perinatal outcome: a prospective study. J Preg Child Health. 2015;2:171.

Cite this article as: Patnaik M, Tejaswini M, Rath SK, Naaz SA. Role of admission cardiotocography and amniotic fluid index on perinatal outcome in low risk pregnancy at term. Int J Reprod Contracept Obstet Gynecol 2021;10:1591-5. 